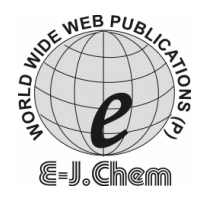

http://www.e-journals.net
ISSN: 0973-4945; CODEN ECJHAO

E-Journal of Chemistry

2010, 7(3), 1018-1022

\title{
A Study of Superficial Sediments and Aquifers in Parts of Uyo Local Government Area, Akwa Ibom State, Southern Nigeria, Using Electrical Sounding Method
}

\author{
U. F. EVANS ${ }^{\#}$, N. J. GEORGE* , A. E. AKPAN, \\ I. B.OBOT ${ }^{\S}$ and A. N. IKOT ${ }^{\mathbb{I}}$ \\ \#Department of Sciences, Maritime Academy of Nigeria. Oron, Nigeria. \\ Department of Physics, University of Calabar, Calabar, Nigeria. \\ *Department of Science Technology, \\ Akwa Ibom State Polytechnic, Ikot Osura, Ikot Ekpene, Nigeria.

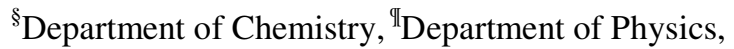 \\ University of Uyo, Uyo, Nigeria. \\ proffoime@yahoo.com
}

Received 18 September 2009; Accepted 10 November 2009

\begin{abstract}
Resistivity sounding method using Schlumberger electrodes configuration was employed to investigate the goe-eletrical properties of the subsurface in parts of Uyo Local Government Area of Akwa Ibom State, Nigeria. Within the maximum electrode spread, the area studied show sandy beds with five layers of various thicknesses. The subsurface sediment harbours a thick aquifer buried in $20.0 \mathrm{~m}$ from the surface of the earth and it is exposed to earth surface at VES 13 and 14 . The resistivity range for the aquifer layer is between 1,050 - 9,300 $\Omega \mathrm{m}$ and thickness is above $80.0 \mathrm{~m}$.
\end{abstract}

Keywords: Uyo, Aquifer, Sediments, Aquifers, Electrical sounding method.

\section{Introduction}

Water is one of the most essential gifts of life. It differs from others because its usage is unlimited. The indices of developmental impulses in any society depend largely on water. Besides drinking, water is traditionally used for agriculture, domestic purposes, spiritual purposes, religion and entertainment/recreation ${ }^{1}$. It is not undoubtful that any economy can rightfully survive without a reliable source of water. Before the industrial revolutions, 
the sources of supply of quality water included rainfall, rivers, stream, dews and ponds. However, all these sources are degraded due to the high level of contamination. The degree of contamination of surface sources of water and the increasing population heightens the demand for quality sources of water. According to Mayer ${ }^{1}$, the demand for water at homes, churches, mosques, industries, farms, recreations, transportations, hospital and schools is increasing day by the day. It is not unlikely that the trend will continue as far as there have not been any alternative to water. The alternative source of quality water that complements the degraded surface water supply is the groundwater. Today, one can witness the increasing number of boreholes drilled by the governments, non-governmental organizations and individuals. It is not astonishing that a number of boreholes failed due to insufficient information on the subsurface geology of the site. While acknowledging the drilling of the subsurface to have information on the subsurface geology in a particular location, it is cost effective to get such information in an analog form over the entire area surveyed using geophysical techniques which do not involve actual drilling. Geophysical survey involves taking measurements of the subsurface at or near the earth's surfaces that are influenced by the internal distributions of physical properties of interest. Resistivity is one of such physical properties. The resistivity of rocks varies because of the inhomogeneuos nature of the subsurface. Sounding methods have been proved to be useful in delineating water bearing rocks ${ }^{2-5}$. Analysis of resistivity sounding data reveals how the resistivity of the subsurface varies with depth. The information derived from the analysis can be used to produce a resolved picture of the subsurface geology. For instance, the resisitivity picture at Ukanaufun Local Government Area, Akwa Ibom State, Nigeria, shows a wider range (385-6860 $\Omega \mathrm{m}$ ) in the top soil which indicates change in facies of the layer ${ }^{6}$. Particularly, resistivity sounding method was used to investigate the electrical properties of sediments in parts of Uyo Local government Area, Akwa Ibom State, Nigeria, in an attempt to identity the aquifer for the area. The study area lies between latitude $5^{0} .00^{\prime} \mathrm{N}$ and $5^{\circ} .05^{\prime} \mathrm{N}$ and longitude $7^{0} .50^{\prime} \mathrm{E}$ and $7^{0} .75^{\prime} \mathrm{E}$ in Akwa Ibom State, Nigeria.

The study area is located in the equatorial rain forest belt, which is characterized by wet and dry seasons. The wet season usually starts in March and ends in October, while the dry season begins in November and ends in February. The difference in the two seasons is noticed by a drop in the amount of rainfall from $380 \mathrm{~mm}$ to $68 \mathrm{~mm}$. The drop in the amount of rain fall may result in the failure of shallow wells. The study area is a gentle undulating low land, whose height varies between $50 \mathrm{~m}$ to $73 \mathrm{~m}$ above the sea level.

The geographic positioning system (G.P.S) shows that the study area lies within the deltaic depositional environment of the Southern Nigeria. The upper most unit of this environment is the Coastal Plain sand which is known as Benin Formation. The Benin Formation is about $6000 \mathrm{ft}$ thick and comprises sand of different grain sizes with intercalations of shale $\mathrm{7}^{7-10}$. Benin Formation is the youngest deposit in the deltaic environment and it harbours prolific aquifers ${ }^{11,12}$.

\section{Experimental}

Using resistivity sounding method with Schlumberger electrodes configuration, geophysical investigation of the subsurface was conducted in the study area. Fourteen soundings were carried out along a profile of about $11,000 \mathrm{~m}$ in length. The maximum current electrode separation for each sounding ranged between $600-800 \mathrm{~m}$. This separation 
This separation determined the extent to which the injected current penetrates the subsurface. The resistance of the subsurface was measured on the surface of the earth using SAS 300 model ABEM Terrameter. The measured resistances were recorded against the corresponding half current electrode separation $\left({ }^{\mathrm{AB}} / 2\right)$ and the potential electrode separation (MN) shown in Figure 1.

The measured resistances were multiplied by the geometrical factor for Schlumberger electrodes array to obtain the resistivity values. The resistivity values were plotted on a bilogorithimic graph against half the current electrode separation. The plot helps to determine whether or not the field data can be interpreted. The data from the bilogorithimic graph were modeled electronically in two relative types of computer programme - forward and iterative least square modelings. The result obtained from the later modeling yielded resistivity values for each sounding (VES station). The thickness of the layers were determined from the depth to bottom of the layers (Table 1). The lithologies of drilled boreholes were used to classify the geoeletrical layers into sediments of different grain sizes (Table 2). The resistivity picture of the study was produced using the geophysical survey data and the lithology log of the drilled borehole.

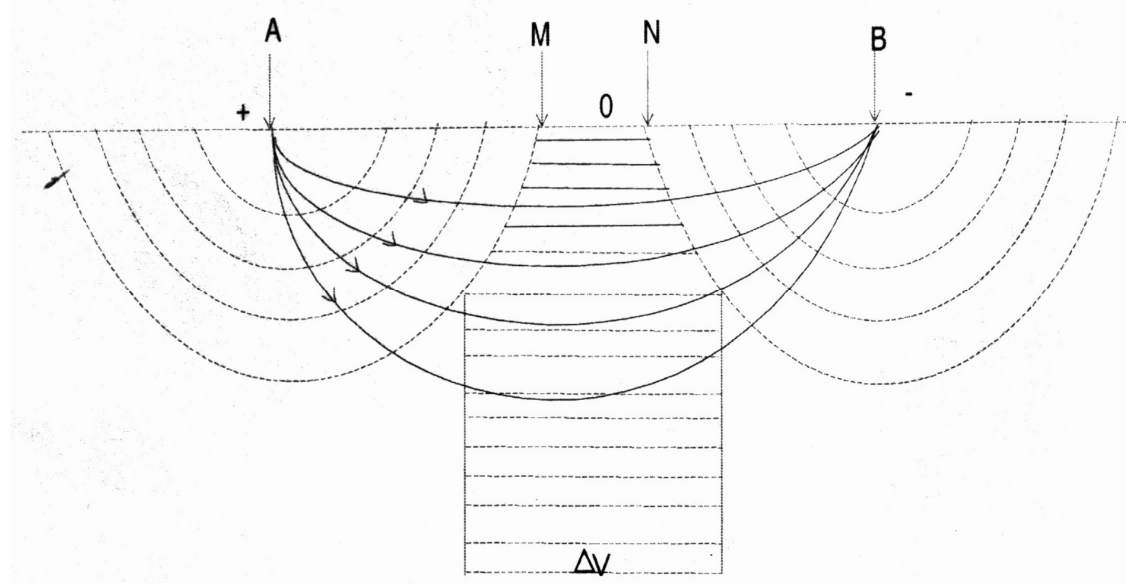

Figure 1. Schlumberger array with current (bold) and equipotential (dotted) lines.

\section{Results and Discussion}

The geophysical survey identifies five goe-electrical layers. The first layer is a Loamy top soil with resistivity range 120-334 $\Omega \mathrm{m}$; the second layer is medium grained sand with resistivity range $707-8,208 \Omega \mathrm{m}$. The third layer is a sandy clay layer with resistivity range of $105-920 \Omega \mathrm{m}$. The fourth layer is medium- coarse grained sand having resistivity range between 1, 050-9,300 $\Omega \mathrm{m}$ and the fifth layer is sandstone with resistivity range 10,400 $92,000 \Omega \mathrm{m}$. The inversion in resistivity of the third layer is explained by the intercalations of clay formed in the layer. The result shows that the study area is a sandy formation of different grain sizes. This result conforms with the literature value $\mathrm{e}^{7-10}$ of a typical coastal plain sand. The aquifer identified for the area is buried $20.0 \mathrm{~m}$ depth and intercepted the surface of the earth at Obio Offot (VES 13 and VES 14). This zone is susceptible to surface contamination. The aquifer is a layer of medium-coarse grained sandy with resistivity range of 1,050 -9,300 $\Omega \mathrm{m}$ and the thickness is above $80.0 \mathrm{~m}$. 
Table 1. Summary of vertical electrical sounding results from computer modeling.

\begin{tabular}{|c|c|c|c|c|c|c|c|c|c|c|c|c|c|c|c|c|c|c|}
\hline \multicolumn{9}{|c|}{ Resistivities of layers in ohm metre } & \multicolumn{5}{|c|}{ Thickness of layers in metre } & \multicolumn{5}{|c|}{$\begin{array}{l}\text { Depth to bottom of layers in } \\
\text { metre }\end{array}$} \\
\hline Location & $\begin{array}{c}\text { Number of } \\
\text { layers }\end{array}$ & & $P_{1}$ & $P_{2}$ & $P_{3}$ & $P_{4}$ & $P_{5}$ & $P_{6}$ & $\mathrm{~T}_{1}$ & $T_{2}$ & $\mathrm{~T}_{3}$ & $\mathrm{~T}_{4}$ & $\mathrm{~T}_{5}$ & $D_{1}$ & $\mathrm{D}_{2}$ & $D_{3}$ & $\mathrm{D}_{4}$ & $D_{5}$ \\
\hline 1 & Atan Offot & 5 & 254 & 1220 & 490 & 2300 & 5480 & - & 0.56 & 4.54 & 6.30 & 91.60 & 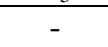 & 0.56 & 5.1 & 11.4 & 103.0 & - \\
\hline 2 & Atan Offot & 5 & 160 & 3980 & 106 & 3810 & 4000 & - & 0.80 & 2.40 & 7.60 & 87.30 & - & 0.80 & 3.2 & 10.8 & 98.1 & - \\
\hline 3 & Atan Offot & 6 & 192 & 708 & 190 & 5820 & 7050 & 65000 & 0.45 & 0.85 & 1.06 & 36.30 & 62.80 & 0.45 & 1.3 & 2.9 & 39.2 & 102.0 \\
\hline 4 & Atan Offot & 6 & 341 & 2540 & 175 & 1660 & 1130 & 82000 & 0.44 & 3.46 & 1.70 & 36.00 & 56.40 & 0.44 & 3.9 & 5.6 & 41.6 & 98.0 \\
\hline 5 & Obio Etioi & 6 & 124 & 3200 & 920 & 1700 & 1610 & 26500 & 0.87 & 1.23 & 3.20 & 42.20 & 54.50 & 0.87 & 2.1 & 5.3 & 47.5 & 102.0 \\
\hline 6 & Obio Etioi & 6 & 344 & 5300 & 437 & 7380 & 5310 & 76100 & 0.3 & 1.20 & 2.40 & 33.36 & 61.50 & 0.30 & 1.5 & 3.9 & 37.5 & 99.5 \\
\hline 7 & Obio Etioi & 6 & 215 & 3400 & 532 & 737 & 1270 & 28300 & 0.46 & 1.14 & 2.10 & 32.80 & 63.00 & 0.46 & 1.6 & 3.7 & 36.5 & 99.5 \\
\hline 8 & Obio Etioi & 5 & 120 & 2190 & 303 & 4480 & 15600 & - & 0.52 & 8.38 & 5.70 & 83.90 & - & 0.52 & 8.9 & 14.6 & 98.5 & - \\
\hline 9 & Obio Etioi & 6 & 329 & 6850 & 745 & 8400 & 5260 & 34500 & 1.1 & 2.30 & 3.10 & 28.70 & 64.90 & 1.10 & 3.4 & 6.5 & 35.2 & 100.1 \\
\hline 10 & Obio Etioi & 6 & 187 & 4680 & 403 & 6350 & 1500 & 10400 & 0.76 & 1.84 & 1.80 & 15.90 & 67.10 & 0.76 & 2.6 & 4.4 & 29.9 & 99.3 \\
\hline 11 & Obio Etioi & 6 & 169 & 2610 & 105 & 5080 & 6410 & 10400 & 0.75 & 1.84 & 1.80 & 15.90 & 67.10 & 0.76 & 2.6 & 4.4 & 29.9 & 97.0 \\
\hline 12 & Obio Etioi & 5 & 2380 & 459 & 8200 & 1920 & 97000 & - & 0.48 & 2.72 & 12.60 & 79.30 & - & 0.48 & 3.2 & 16.8 & 96.1 & - \\
\hline 13 & Obio Etioi & 5 & 188 & 1160 & 9300 & 8200 & 59800 & - & 0.38 & 9.52 & 15.20 & 90.00 & - & 0.38 & 9.9 & 25.1 & 95.1 & - \\
\hline 14 & Obio Etioi & 6 & 212 & 2960 & 5410 & 2370 & 1140 & 57200 & 0.29 & 0.91 & 2.30 & 29.4 & 58.40 & 0.29 & 1.2 & 3.2 & 32.6 & 91.0 \\
\hline
\end{tabular}

Table 2. Ranges for resistivity of rocks in the soil

\begin{tabular}{lc}
\hline \multicolumn{1}{c}{ Rock Type } & Resistivity, $\Omega \mathrm{m}$ \\
\hline Loamy topsoil & $120-334$ \\
Medium grained Sands & $708-8,200$ \\
Sandy Clay & $105-920$ \\
Medium-Coarse & $1,050-9,300$ \\
Grained Sands & $10,400-97,000$ \\
Sandstones &
\end{tabular}




\section{Conclusion}

From the above results, vertical electrical sounding employing Schlumberger electrode configuration thrives in showing that parts of Uyo Local Government Area surveyed, extensively have sandy units of various grain sizes. The area has thick and prolific aquifer which cannot influence by seasonal climatic changes. The boreholes drilled in the area should cut across reasonable section of the aquifer in order to have a prolific well that will reduce the rate of dependency of settlers on polluted or contaminated surface water. Since wells located near VES 13 and 14 are prone surface contaminations, borehole drilled here should be regularly checked for water quality.

\section{Recommendation}

Based on the results of the study, the following recommendations are made, such that their implementations will minimize the problem of water supply in Uyo Local Government Area.

1. Borehole should be drilled to a minimum depth of $40.0 \mathrm{~m}$ for private and commercial uses in the study area for reliable supply of water.

2. Borehole drillers should avoid drilling at VES 13 and VES 14 or water quality test should be periodically conducted for wells within the stipulated locations in order to guard against contamination.

\section{References}

1 Mayer U, Chemistry of Hazardous Material. Occasion paper, 14. Water issue Studies. School of Countation and African Studies, London, University of London, 2005, 73-80.

2. Akpan F S, Etim O N and Akpan A E, Nigerian J Phys., 2006, 18, 39-44.

3. Hnatiuk J and Randall A. G, Canadian J Earth's Sci., 1981, 14 (3), 31- 44.

4. Edet A E and Okereke C, S, J African Earth's Sci., 2002, 35, 433-443.

5. Bhattacharya P K and Petra H P, Elsevier Sci, Publications, 1968, 4-7.

6. Okereke C S, Esu E O and Edet A E, J African Earth's Sci., 1998, 27(1), 149-163.

7. Edet A E, Merket B J and Offiong O E, Environmental Geology, 2003, 44, 137-149.

8. Edet A E and Okereke C S, J African Earth Sci., 2002, 35, 433-443.

9. Reijers T J A and Peters S. W, Geologie en Mijnbouw, 1987, 76, 197-215.

10. Mbipom E W, Okwueze E E and Ouwuegbuche A A, Nigerian J Phys., 1996, 3, 82.

11. Chernicoffs and Venkatakrishnan R, An Introduction to Physics Geology. New York, Worth Publishers Incorporated, 1995, 115-120.

12 Short K C and Stauble A J, American Applied Physical Geology Buletin, 1976, 15, 761-7791. 


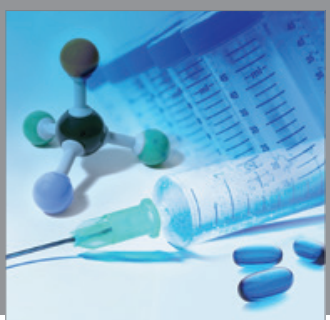

International Journal of

Medicinal Chemistry

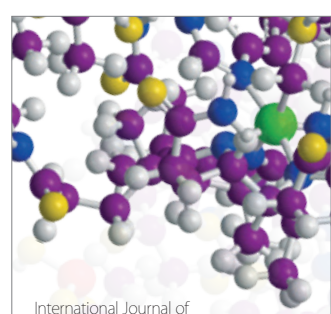

Carbohydrate Chemistry

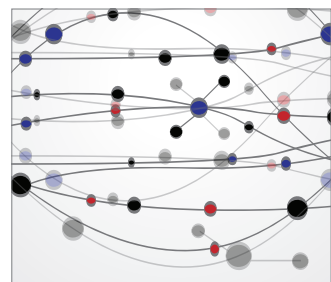

The Scientific World Journal
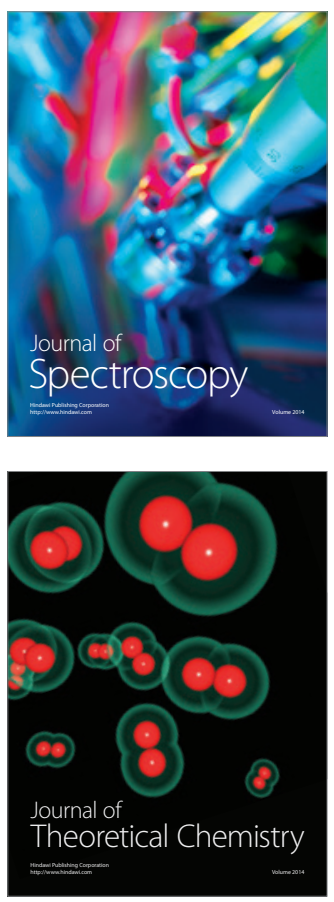
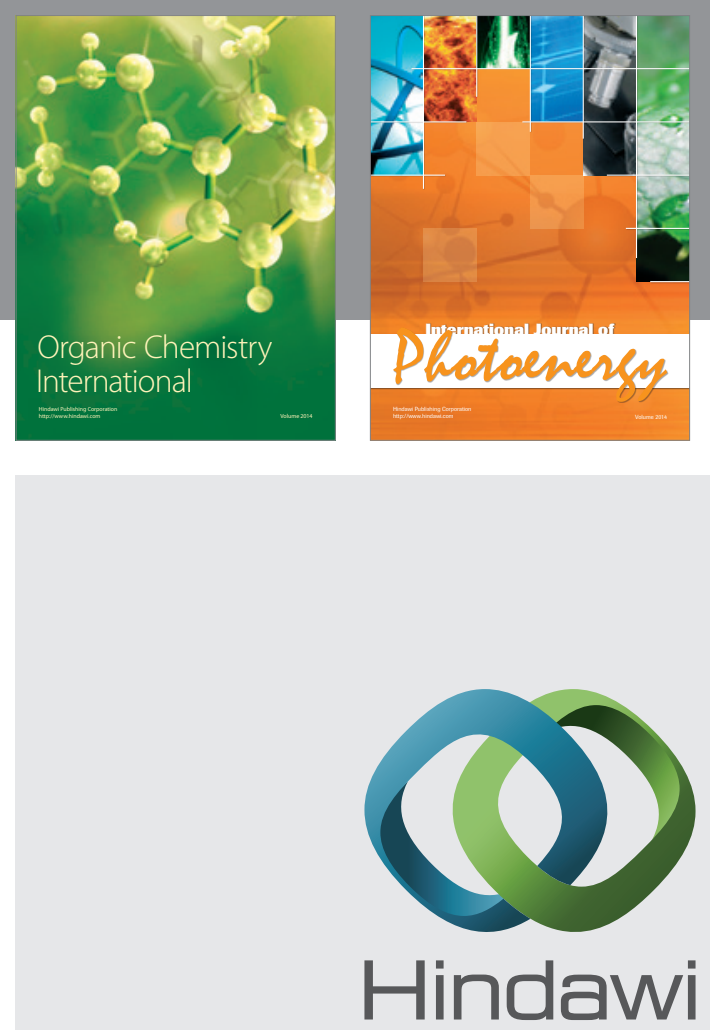

Submit your manuscripts at

http://www.hindawi.com
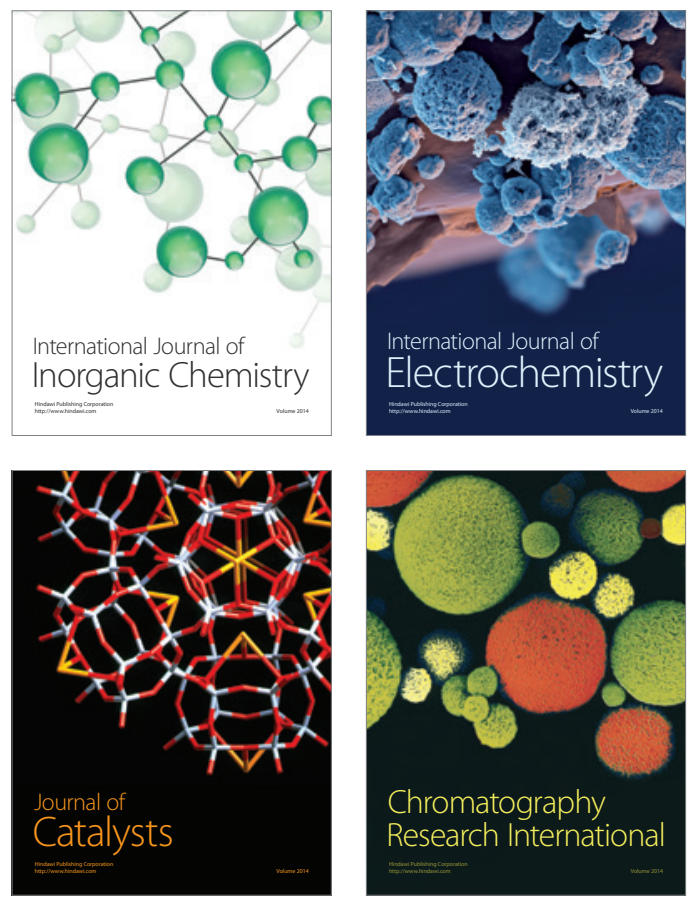
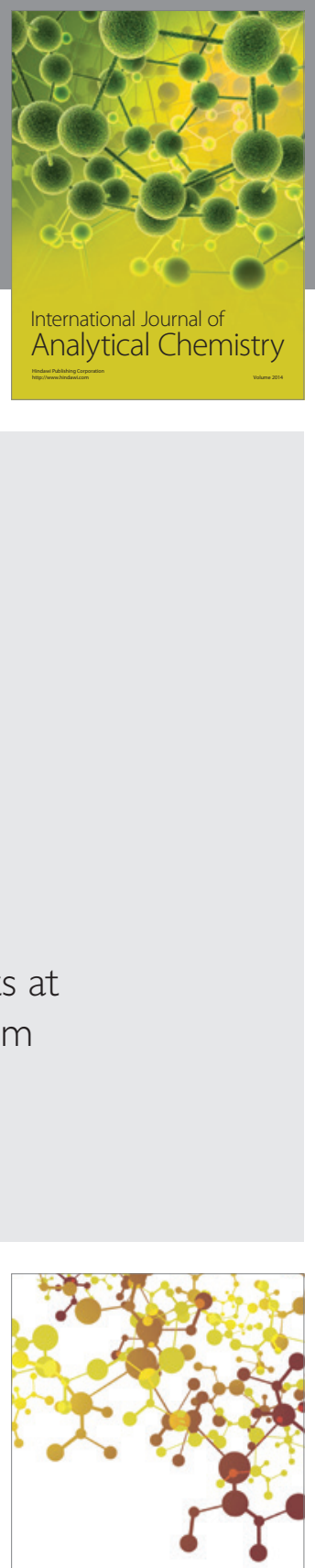

Journal of

Applied Chemistry
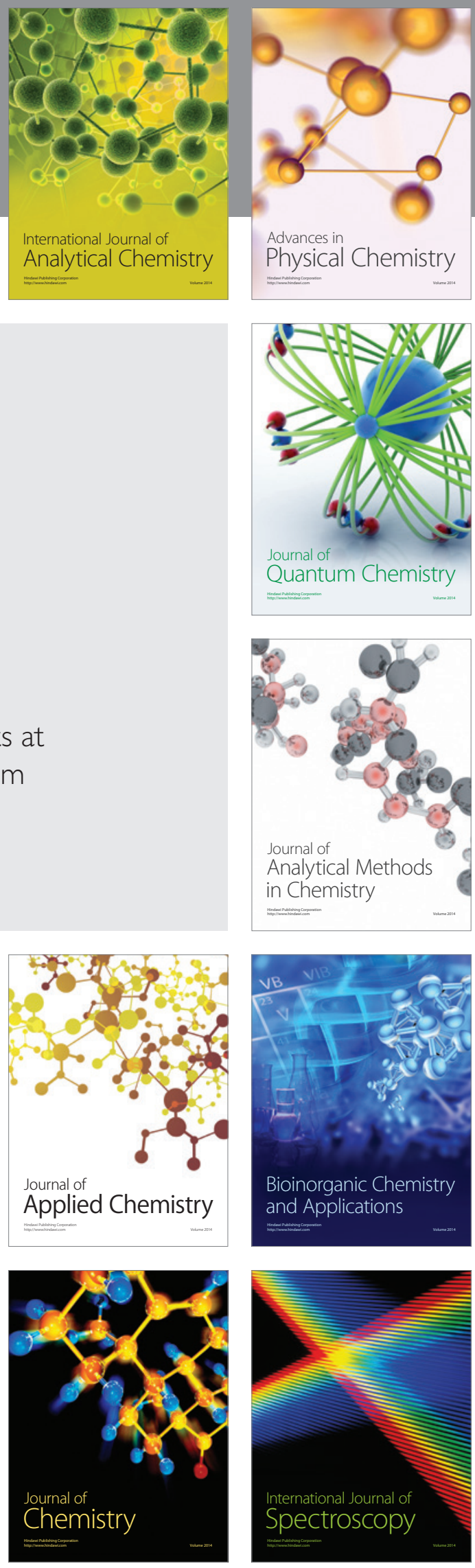